\title{
SISTEMAS DE AVALIAÇÃO DOS ESTADOS NO BRASIL: AVANÇOS DO GERENCIALISMO NA EDUCAÇÃO BÁSICA
}

Regiane Helena Bertagna Raquel Fontes Borghi ${ }^{(*)}$

O presente texto tem por objetivo discutir os avanços do "gerencialismo" na educação básica brasileira, a partir do mapeamento de sistemas de avaliação estaduais, realizado no âmbito de pesquisa desenvolvida pelo GREPPE (Grupo de Estudos e Pesquisas em Política Educacional)1. Desta forma, se pretende elucidar possíveis estratégias da introdução de "privatização encoberta", "privatização endógena" (BALL; YODELL, 2008), e, consequentemente, de processos de privatização da educação básica no Brasil induzidos por meio de pressupostos referenciados na lógica de mercado.

Para tanto, apresentaremos um recorte do mapeamento realizado acerca da existência de sistemas estaduais de avaliação em larga escala nos diferentes estados brasileiros e Distrito Federal, bem como a caracterização realizada a partir dos dados de ano de inicio do sistema de avaliação estadual e periodicidade da aplicação das avaliações.

A metodologia de pesquisa de abordagem qualitativa (BOGDAN; BIKLEN, 1994) se constituiu de levantamento nos sítios das secretarias estaduais de educação e em sítios dos próprios sistemas de avaliação, quando estavam disponíveis para acesso. O período considerado foi o mesmo da pesquisa a qual este texto está vinculado (2005-2015), tendo em vista a Lei de Responsabilidade Fiscal como possível indutora de processos de privatização da educação básica no Brasil.

Desta forma, se pretendeu compreender como a ampliação dos sistemas de avaliação podem se tornar uma estratégia para fortalecimento de ideias de cunho gerencialista, favorecendo a introdução da lógica de mercado nos serviços públicos.

Sader (2003) afirma que a mercantilização da educação não requer necessariamente a privatização do fornecimento/propriedade. Embora formalmente estatal, uma instituição pode ter

\footnotetext{
${ }^{(*)}$ Regiane H. Bertagna. Docente no Departamento de Educação, Instituto de Biociências de Rio Claro, Universidade Estadual Paulista Júlio de Mesquita Filho.

Raquel F. Borghi. Docente no Departamento de Educação, Instituto de Biociências de Rio Claro, Universidade Estadual Paulista Júlio de Mesquita Filho.

${ }^{1}$ O Grupo de Estudos e Pesquisas em Política Educacional (GREPPE) é de natureza interinstitucional composto por pesquisadores de três universidades públicas do Estado de São Paulo: UNICAMP, USP e UNESP. A pesquisa aqui referida é intitulada: "Estratégias de privatização da educação básica no Brasil (2005-2015)", coordenada pela Profa. Dra. Theresa Adrião e financiada pelo CNPq.
} 
objetivos privados (atender ao mercado) e um funcionamento orientado por pressupostos liberais, tais como: o individualismo, a competição entre os indivíduos e, genericamente, uma concepção de mundo operacional ao capital.

É neste sentido que a "tipologia" de Ball e Yodell (2008) acerca dos processos de privatização nos interessa aqui. Para eles, são muitas as formas de privatização evidentes em políticas educacionais de alguns governos nacionais e internacionais. Os autores afirmam que algumas formas são denominadas diretamente de privatização, mas em muitos casos, a privatização permanece encoberta como consequência de reformas (educativas). Os autores abordam tais processos a partir de dois grandes grupos - a privatização exógena e a privatização endógena.

A primeira delas - privatização exógena implica na abertura dos serviços de educação pública para a participação do setor privado; o segundo grupo - privatização endógena, implica na importação de ideias, métodos e práticas do setor privado com o propósito de fazer com que o setor público se assemelhe cada vez mais a uma empresa e, ainda, seja tão eficiente quanto uma empresa (BALL; YODELL, 2008).

Nas palavras de Hypólito, Gandin (2013) trata-se da gestão pública assumindo procedimentos ou adotando padrões do setor privado, sob a alegação de ser necessária para a produção de qualidade educacional. Neste sentido, o setor público assume o modelo gerencial como referência para a organização do trabalho da escola e introduz, por exemplo, diferenciações de remuneração por produtividade, procedimentos de medida de qualidade por resultados, ações de estímulo à competividade entre profissionais e unidades escolares.

Santos (2012), em seu livro Pedagogia do Mercado lança luz sobre a abrangência da atuação privada na educação:

Todo o processo de produção pedagógica é submetido à lógica do mercado: gestão escolar, relações ensino aprendizagem, conteúdos programáticos, princípios pedagógicos do currículo e avaliação dos resultados. O sentido e as finalidades da educação incorporam a mercadorização já no âmbito da produção. (SANTOS, 2012, p. 20)

Neste sentido, também Ball e Yodell (2008) destacam a abrangência dos processos atuais de privatização:

No son solamente la educacion y los servicios educativos los que están sometidos a diversas formas d eprivatizacion, sino que también se está privatizando la própria política educativa, a través del asesoramiento, la consula, la investigación, las evaluacionaes y otros médios de influencia" (BALL; YODELL, 2008, p. 11) 
É neste sentido que afirmamos que os atuais processos de gerencialismo no campo da educação são, em última instância, estratégias de privatização.

No Brasil, nos anos 90, a Reforma do Estado foi proposta pelo Ministério da Administração e Reforma do Estado (MARE), por meio do Plano Diretor de Reforma do Aparelho de Estado (PDRAE), elaborado durante o primeiro mandato do Governo do presidente Fernando Henrique Cardoso (1995-1998). Este documento cumpriu papel norteador para a reorganização do Estado brasileiro e a implantação de uma administração gerencial. O Plano assim justifica a necessidade da Reforma:

É importante ressaltar que a redefinição do papel do Estado é um tema de alcance universal nos anos 90. No Brasil esta questão adquiriu importância decisiva, tendo em vista o peso da presença do Estado na economia nacional: tornou-se, consequentemente, inadiável equacionar a questão da reforma ou da reconstrução do Estado, que já não consegue atender com eficiência a sobrecarga de demandas a ele dirigidas, sobretudo na área social. A reforma do Estado não é, assim, um tema abstrato: ao contrário, é algo cobrado pela cidadania, que vê frustrada suas demandas e expectativas. (BRASIL, 1995, p. 10).

O diagnóstico que se apresenta no PDRAE é o da crise do estado e de sua forma de administração - burocrática:

A crise do Estado define-se então (1) como uma crise fiscal, caracterizada pela crescente perda do crédito por parte do Estado e pela poupança pública que se torna negativa; (2) o esgotamento da estratégia estatizante de intervenção do Estado, a qual Plano Diretor da Reforma do Aparelho do Estado 11 se reveste de várias formas: o Estado do bem-estar social nos países desenvolvidos, a estratégia de substituição de importações no terceiro mundo, e o estatismo nos países comunistas; e (3) a superação da forma de administrar o Estado, isto é, a superação da administração pública burocrática. (BRASIL, 1995, p. 11).

Para a superação da administração pública burocrática a proposta é de uma administração gerencial. Conforme explicitado no PDRAE, a diferença fundamental está na forma de controle. Na administração burocrática o controle é centrado nos processos, enquanto na gerencial ele está concentrado nos resultados. As estratégias da administração gerencial contidas no Plano estão descritas abaixo:

Na administração pública gerencial a estratégia volta-se (1) para a definição precisa dos objetivos que o administrador público deverá atingir em sua unidade, (2) para a garantia de autonomia do administrador na gestão dos recursos humanos, materiais e financeiros que lhe forem colocados à disposição para que possa atingir os objetivos 
contratados, e (3) para o controle ou cobrança a posteriori dos resultados. (BRASIL, 1995, p. 22).

Para a nossa discussão interessa a última estratégia "controle ou cobrança a posteriori dos resultados". É neste contexto que se amplia e, se consolida na área educacional, a implantação dos sistemas de avaliação no Brasil.

Para Hypólito (2010), o modelo gerencialista de administração implementado no Brasil fundamenta a introdução de políticas regulativas. Desta forma, o modelo gerencial é apresentado como solução para os problemas da educação e, a avaliação externa em larga escala passa a ser um importante instrumento de regulação.

A introdução de sistemas de avaliação da educação e do desempenho docente é crucial para essa regulação por parte do Estado, que passa a controlar e avaliar desde longe, por meio da contratação de terceiros para realizar a avaliação externa - considerada como prestação de contas à sociedade civil (accountability). Tais modelos gerenciais são baseados na qualidade e no mérito e os problemas da educação ficam reduzidos a problemas técnico-gerenciais. (HYPÓLITO, 2010, p. 1339).

Segundo Hypólito (2010), a criação de um sistema de prestação de contas, baseada em avaliações externas em larga escala, com o intuito de identificar estudantes e escolas que fracassam e, posteriormente, penalizá-los pelo desempenho escolar sem que se considere o contexto social em que a instituição de ensino está inserida, é um exemplo da expansão do ideário de mercado no cenário educacional, dentro da lógica gerencial.

As diretrizes educacionais do Estado brasileiro vêm sendo desenvolvidas, ao longo das últimas décadas, com inúmeras ações que demonstram, de forma inequívoca, uma coerência com tais políticas. Exemplos dessas políticas podem ser encontrados tanto em ações nacionais e internacionais, como em ações no âmbito dos estados federados. Caracterizam-se por estabelecer um sistema de avaliação abrangente, que aponta as medidas de desempenho do sistema e dos níveis de ensino, donde partem as soluções e metas técnicas capazes de solucionar os impasses da educação pública. (HYPÓLITO, 2010, p. 1343).

Segundo Carneiro (2013, p. 132-133), “[...] as avaliações externas e de larga escala vêm se configurando como uma ferramenta de gerenciamento e controle, em correspondência à crescente introdução de mecanismos mercadológicos na educação" e, tanto no contexto internacional (NEWMAN e CLARK, 2012), quanto no contexto brasileiro, políticas educacionais e avaliativas, nessa perspectiva, encontram solo fértil para sua proliferação. Nesse sentido, observamos que podem ser nomeadas e explicitadas de diversas maneiras por diferentes autores que apontam para 
introdução dessa lógica, tais como: Ball (2005); Lima (2012); Afonso (2012) "cultura do desempenho"; Freitas (2012); Ravitch (2011); Maués (2009) “cultura dos resultados”; entre outros.

No Brasil, percebe-se essa tendência presente desde períodos anteriores (FREITAS, 2007) e, também, na configuração do Plano Nacional da Educação (PNE) (BRASIL, 2014). Filipe e Bertagna (2015) após análise das metas e estratégias do documento (PNE) identificaram em relação à avaliação que:

Depreende-se da análise do novo PNE, no que tange à avaliação e à qualidade educacional, que o documento possui avanços, mas também retrocessos, sendo que os últimos, muitas vezes impedem a consecução dos primeiros. Isto é perceptível na concepção de qualidade prevista na meta 7 do documento, que reduz a qualidade educacional ao cumprimento do IDEB, desconsiderando os processos educacionais, e na concepção de avaliação institucional que fica aprisionada e a mercê do referido na meta 7, limitando seu potencial na produção da qualidade da educação.

Além disso, percebe-se o atravessamento dos interesses do setor privado em todo o PNE, como, por exemplo, a ampliação do percentual do PIB para investimento em educação, que demonstra um avanço; mas ao ampliar a noção de público, inclui nesse percentual isenções para a iniciativa privada em programas tais como: o ProUni, o Fies, creches conveniadas e outros. A partir das discussões é possível inferir que as concepções de avaliação e qualidade da educação presentes no novo PNE possuem um caráter mercantilizado.

Nessa lógica, a qualidade educacional significa o cumprimento de metas estabelecidas externamente às escolas por meio das avaliações em larga escala, que servem para responsabilizar o professor ou a instituição escolar pelo seu fracasso. (FILIPE; BERTAGNA, 2015, p. 63-64).

É importante destacar que a compreensão da avaliação em larga escala pode ser definida como "[...] um instrumento de acompanhamento global de redes de ensino com o objetivo de traçar séries históricas do desempenho dos sistemas, que permitem verificar tendências ao longo do tempo, com a finalidade de reorientar políticas públicas.” E que “[...] quando conduzidas com metodologia adequada podem trazer importantes informações sobre o desempenho dos alunos, dados sobre os professores, condições de trabalho e funcionamento das escolas de uma rede." (FREITAS, et al, 2012, p. 47).

No entanto, “[...] criou-se, além deste objetivo, a ilusão de que avaliações de larga escala possam avaliar também a escola e os professores [...]” (FREITAS et al., 2012, p. 47), de forma que 
as avaliações de redes de ensino em larga escala, cuja finalidade deveria ser de orientar as políticas públicas, ganham centralidade no Brasil e no mundo.

No âmbito da educação básica, a consolidação do Sistema de Avaliação da Educação Básica (SAEB) no Brasil, tendo ao longo do período modificado os objetivos, finalidades, bem como as técnicas de coleta e processamento de dados e, seu alcance, de acordo com os diferentes períodos históricos e políticos (BONAMINO; SOUSA, 2012; FREITAS, 2007), acabou acarretando e influenciado a criação de sistemas de avaliação em larga escala em nível estadual e, ainda em alguns casos, municipais, como apontam Bauer e Tavares (2013).

Em 2007, o governo federal por meio do Instituto Nacional de Estudos e Pesquisas Educacionais Anísio Teixeira (INEP) criou o Índice de Desempenho da Educação Básica (IDEB), um indicador de qualidade educacional que combina o desempenho em avaliações em larga escala (Prova Brasil e SAEB) com informações sobre a taxa de aprovação, retenção e evasão escolar. Segundo o INEP (2012), o objetivo do IDEB é monitorar o sistema de ensino do país, diagnosticando e norteando ações voltadas para a melhoria do sistema. Este indicador deve, então, detectar as escolas cujos alunos apresentam baixa performance nas avaliações em larga escala e monitorar sua evolução.

Tendo como referência a constituição, aperfeiçoamento e consolidação do Sistema Nacional de Avaliação da Educação Básica (SAEB), bem como o estabelecimento de metas indicados pelo IDEB, muitos estados criaram o seu próprio sistema de avaliação (BONAMINO e SOUSA, 2012).

Em estudos realizados sobre a expansão dos sistemas de avaliação nos estados brasileiros encontramos Bauer e Tavares (2013) que sinalizaram em 2013, a existência de 17 estados brasileiros que possuíam sistema próprio de avaliação, impulsionados pela iniciativa federal.

As autoras revelam ainda que muitos municípios também têm criado o seu sistema de avaliação, mas que não há uma informação sistematizada a respeito de quantos e quais são até o momento. Também colocam, oportunamente, que passados 25 anos da primeira iniciativa e, considerando, as mudanças realizadas nos desenhos das políticas de avaliação, se faz necessário retomar e analisar tais propostas e sistemas de forma a "[...] incorporar na discussão o conhecimento que vem sendo produzido e difundido sobre essas avaliações, seus usos e implicações nas redes de ensino". (BAUER; TAVARES, 2013, p.16). 


\section{DESVELANDO OS SISTEMAS ESTADUAIS DE AVALIAÇÃO DA EDUCAÇÃO (2005- 2015)}

Dos 26 estados brasileiros e o Distrito Federal (DF) a pesquisa identificou que 19 estados mais o DF possuem sistemas de avaliação, totalizando 20, no período considerado pela pesquisa. Para melhor delineamento e descrição dos dados encontrados optamos por apresentá-los no quadro abaixo.

\begin{tabular}{|c|c|c|}
\hline Região Administrativa & $\begin{array}{l}\text { Estados com sistemas próprios de } \\
\text { avaliação }\end{array}$ & Estados sem sistemas próprios de avaliação \\
\hline Região Norte & $\begin{array}{l}\text { Acre (AC) } \\
\text { Amazonas (AM) } \\
\text { Pará (PA) } \\
\text { Rondônia (RO) } \\
\text { Tocantins (TO) }\end{array}$ & $\begin{array}{l}\text { Amapá (AP) - Indica que há uma sistemática de avaliação } \\
\text { realizada. } \\
\text { Roraima (RR) }\end{array}$ \\
\hline Região Nordeste & $\begin{array}{l}\text { Alagoas (AL) } \\
\text { Bahia (BA) } \\
\text { Ceará (CE) } \\
\text { Paraíba (PB) } \\
\text { Pernambuco (PE) } \\
\text { Piauí (PI) } \\
\end{array}$ & $\begin{array}{l}\text { Maranhão (MA) - Há dados referentes a uma iniciativa de } \\
\text { avaliação sistemática. } \\
\text { Rio Grande do Norte (RN) - A partir de } 2016 \text { possui o } \\
\text { Sistema Integrado de Monitoramento e Avaliação } \\
\text { Institucional - SIMAIS. } \\
\text { Sergipe (SE) }\end{array}$ \\
\hline Região Centro-Oeste & $\begin{array}{l}\text { Goiás (GO) } \\
\text { Mato Grosso do Sul (MS) } \\
\text { Distrito Federal (DF) } \\
\end{array}$ & Mato Grosso \\
\hline Região Sudeste & $\begin{array}{l}\text { Espírito Santo (ES) } \\
\text { Minas Gerais (MG) } \\
\text { Rio de Janeiro (RJ) } \\
\text { São Paulo (SP) }\end{array}$ & -- \\
\hline Região Sul & $\begin{array}{l}\text { Paraná (PR) } \\
\text { Rio Grande do Sul (RS) }\end{array}$ & Santa Catarina (SC) \\
\hline
\end{tabular}

Fonte: ADRIÃO, et al., 2018.

Como se pode observar no quadro 1, a região Sudeste é a única região administrativa em que todos os estados a ela pertencentes implantaram sistema de avaliação.

Em alguns dos estados do país, que ainda não possuem sistema de avaliação, identificados na pesquisa, encontramos informações sobre iniciativas de avaliação, como no caso do Amapá (AP) e do Maranhão (MA).

É interessante destacar que o estado de Santa Catarina (SC), em documento produzido pela Secretaria de Educação, esclarece sua opção pela não realização de um sistema próprio de avaliação, pois realiza acompanhamento do desempenho dos alunos do estado a partir das avaliações externas nacionais e internacionais (SANTA CATARINA, 2014). Desta forma, a SEE/SC optou por se orientar pelos dados referentes ao sistema de avaliação nacional, que também fornece dados sobre o estado, e, do Programa Internacional de Avaliação de Estudantes (Programme for International Student Assessment - PISA).

É possível ter uma percepção geral do número de estados de cada região que implantaram sistemas próprios de avaliação no período de 2005-2015, no gráfico abaixo. 
Gráfico 1. Sistemas estaduais de avaliação brasileira por região administrativa (2005-2015).

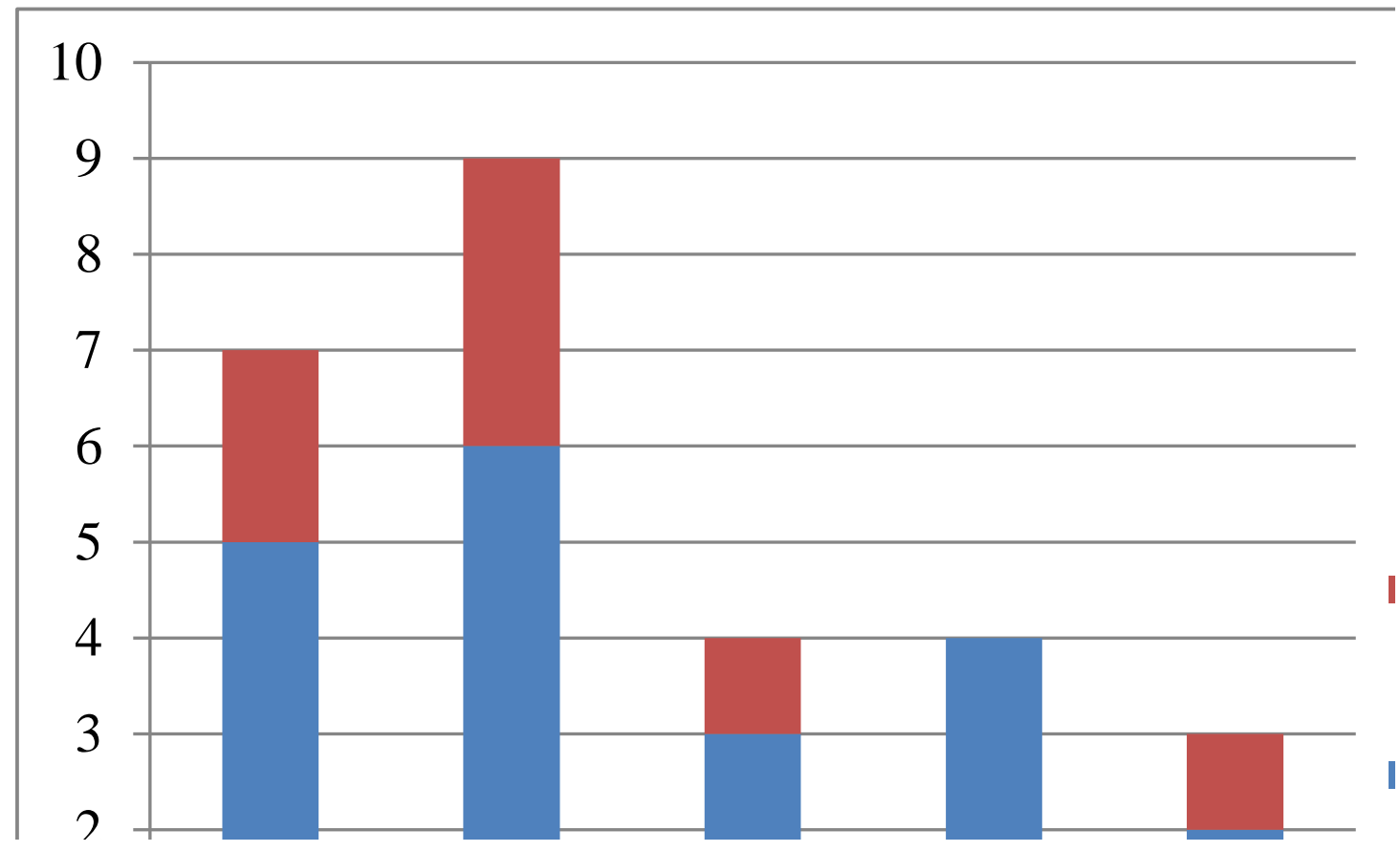

Fonte: ADRIÃO, et al., 2018.

Com relação ao ano de início dos sistemas de avaliação em cada estado, depois de coletado os dados os mesmos foram organizados em três períodos, a saber: sistemas implantados na década de 90; sistemas implantados entre 2000 e 2006 e, sistemas implantados após o início de IDEB (2007-2015). Os dados estão apresentados no gráfico abaixo.

Gráfico 2. Número de implantação de sistemas próprios de avaliação por período

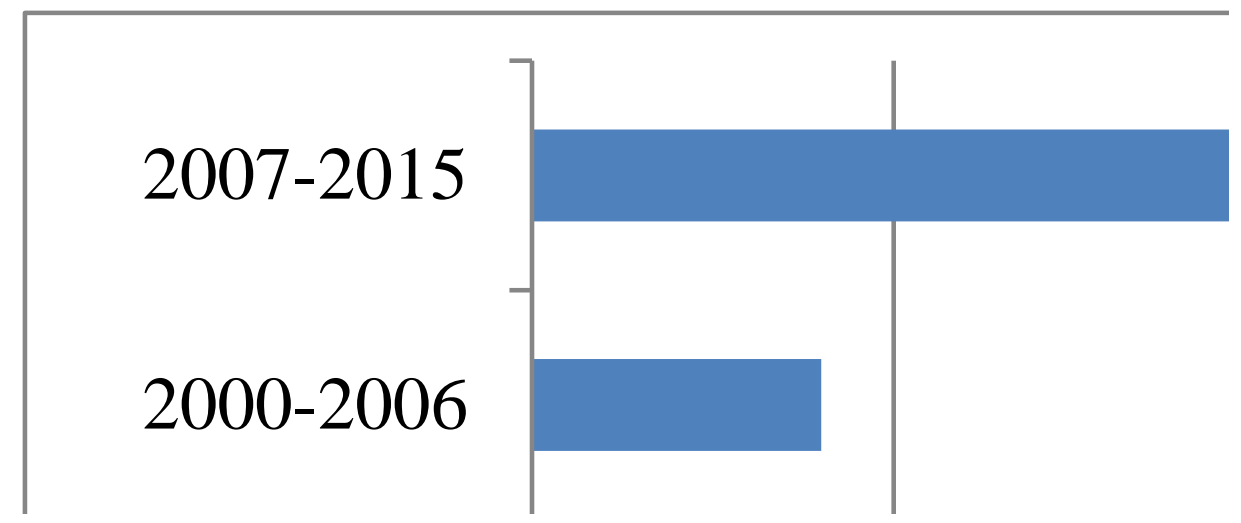

Fonte: ADRIÃO, et al., 2018.

Vale ressaltar que foram considerados os dois primeiros sistemas próprios de avaliação implantados, ainda na década de 90, os dos estados de São Paulo e do Rio Grande do Sul. Embora o estado do Ceará tenha a primeira iniciativa em 1992, em Fortaleza, somente em 2004 se estendeu para todo o estado. O estado de Minas Gerais também teve sua primeira iniciativa em 1992, mas somente em 2000 institucionaliza oficialmente o sistema de avaliação no estado. 
Como se evidencia o maior período de implantação dos sistemas de avaliação estaduais ocorreram após o início de IDEB, totalizando 14 estados, até 2015. Esse aspecto também foi observado por Horta; Junqueira; Oliveira (2016, p. 24): “[...] principalmente a partir de 2007, ano de criação do Ideb, o número de estados que fazem uso de testes como parte de suas ações educacionais tem aumentado. Esse aumento pode estar baseado na crença de que seu uso, por si só, seja capaz de garantir a qualidade da educação".

O mesmo movimento em direção aos testes, à criação de sistemas de avaliação, pode ser observado nos municípios. Pesquisa realizada pelo INEP em parceria com a Fundação Carlos Chagas, junto aos secretários de educação municipais, respondido por 4.309 deles, indicou que 1.784 municípios (41\% dos respondentes) contavam com avaliações próprias e, ainda, que 905 deles (21\% dos respondentes), apesar de não a possuírem, pretendiam desenvolvê-la (BAUER et al., 2015). A maior parte dessas avaliações se refere unicamente a testes aplicados aos alunos, os quais, assim como aconteceu com os estados, também passaram a ser intensificados depois do ano de 2007.

Com relação à periodicidade da aplicação das provas do sistema de avaliação estaduais, se verificou que dezessete (17) estados realizavam anualmente; dois (02) estados indicaram bianualmente e, um (01) estado, da região norte, não obtivemos a informação, conforme apresentamos no quadro abaixo.

Quadro 2. Periodicidade de aplicação da prova
\begin{tabular}{|l|l|l|l|}
\hline Região Administrativa & Anual & Bianual & Sem informação \\
\hline Norte & 4 & 0 & 1 \\
\hline Nordeste & 5 & 1 & - \\
\hline Centro-Oeste & 2 & 1 & - \\
\hline Sudeste & 4 & 0 & - \\
\hline Sul & 2 & 0 & - \\
\hline Total & 17 & 2 & 1 \\
\hline
\end{tabular}

Fonte: ADRIÃO, et al., 2018.

Cabe ressaltar que, em alguns estados, a periodicidade apresentada no quadro 2 não se manteve uniforme durante o período investigado na pesquisa. Ao longo do período de sua existência, podem ter ocorrido interrupções, como é o caso, por exemplo, de Rondônia onde a aplicação é anual, no entanto, houve suspensão no ano de 2014; ou ainda, o estado do Rio Grande do Sul, que iniciou em 1996 e, até 1998 realizava a aplicação em parceria com a Federação das Associações dos Municípios do RS (FAMURS), posteriormente, entre 1999 e 2004, o Estado deixou de realizar as avaliações; e, em 2005, retornou a ser realizado anualmente. 
A questão da periodicidade se revela importante, quando analisada no conjunto de testes realizados pelos alunos, principalmente, se a aplicação ocorrer de maneira censitária, pois informa uma lógica e modela uma cultura de naturalização de provas e testes. Tal lógica incita a competividade e desgasta o trabalho da escola com a intensidade de testes e projeções quantitativas sobre o desempenho dos alunos em determinados conteúdos, como destacam alguns estudos (COSSO, 2013; POLATO, 2014; MELLO, 2014; MENEGÃO, 2016). Tais pesquisas revelam que esta lógica tem gerado consequências para a organização do trabalho da escola, para o currículo, para a atuação dos profissionais da escola e, a conformação a determinada lógica (empresarial, mercantil) de realização sistemática de testes de proficiência e obtenção de metas em detrimento de espaços de formação crítica, política, criativa, artística, física e social dos alunos (BERTAGNA, 2017; SORDI, et al., 2017).

Um aspecto que merece destaque e, incialmente, não estava previsto na pesquisa, mas se revelou instigante, diz respeito à contratação por muitos estados da assessoria do Centro de Políticas Públicas e Avaliação da Educação (CAEd). Ao investigarmos os sistemas de avaliação nos estados, observamos que vários deles se apresentavam com link para o sítio do CAEd. Este fato nos motivou a mapear a relação e obtivemos os dados apresentados no quadro abaixo.

Quadro 3. Sistemas próprios de avaliação nos estados brasileiros (2005-2015) com assessoria ou vinculados CAED

\begin{tabular}{|l|l|l|}
\hline $\begin{array}{l}\text { Região } \\
\text { Administrativa }\end{array}$ & Estados com assessoria CAED & Estados sem assessoria CAED \\
\hline Região Norte & $\begin{array}{l}\text { Acre (AC) } \\
\text { Amazonas (AM) } \\
\text { Pará (PA) } \\
\text { Rondônia (RO) }\end{array}$ & $\begin{array}{l}\text { Amapá (AP) } \\
\text { Roraima (RR) } \\
\text { Tocantins (TO) }\end{array}$ \\
\hline Região Nordeste & $\begin{array}{l}\text { Alagoas (AL) } \\
\text { Bahia (BA) } \\
\text { Ceará (CE) } \\
\text { Paraíba (PB) } \\
\text { Pernambuco (PE) } \\
\text { Piauí (PI) }\end{array}$ & $\begin{array}{l}\text { Maranhão (MA) } \\
\text { Rio Grande do Norte (RN) } \\
\text { Sergipe (SE) }\end{array}$ \\
\hline $\begin{array}{l}\text { Região } \\
\text { Oeste }\end{array}$ & $\begin{array}{l}\text { Goiás (GO) } \\
\text { Mato Grosso do Sul (MS) }\end{array}$ & $\begin{array}{l}\text { Mato Grosso (MG) } \\
\text { Distrito Federal (DF) }\end{array}$ \\
\hline Região Sudeste & $\begin{array}{l}\text { Espírito Santo (ES) } \\
\text { Minas Gerais (MG) } \\
\text { Rio de Janeiro (RJ) }\end{array}$ & $\begin{array}{l}\text { São Paulo (SP) } \\
\text { Rio Grande do Sul (RS) }\end{array}$ \\
\hline Região Sul & Santa Catarina (SC) \\
\hline
\end{tabular}

Fonte: ADRIÃO, et al., 2018. 
O quadro 3 evidencia os sistemas de avaliação brasileiros que estavam vinculados ou assessorados pelo CAEd. ${ }^{2}$ Do total de 20 sistemas estaduais de avaliação, 17 possuíam parceria com o CAEd. Nas regiões Nordeste e Sul do país, todos os estados com sistemas estaduais de avaliação dispunham de assessoria do CAEd.

O Centro de Políticas Públicas e Avaliação da Educação, da Universidade Federal de Juiz de Fora (CAEd/UFJF), segundo disponível em seu sítio eletrônico, “[...] é considerado referência nacional na execução de programas de avaliação educacional, na formação de especialistas na área de gestão da educação pública e no desenvolvimento de tecnologias de administração escolar." (CAEd, 2018).

O CAEd atua junto ao Governo Federal, Estados, Municípios, instituições e fundações na realização de avaliações de larga escala com a produção de medidas de desempenho e na investigação de fatores intra e extraescolares associados ao desempenho. Tem como objetivo principal oferecer dados e informações úteis capazes de subsidiar as ações de melhoria da qualidade da educação e equidade nas oportunidades educacionais (CAEd, 2018).

De acordo com sítio do CAEd, o mesmo está organizado em cinco unidades: Unidade de Pesquisa, Unidade de Avaliação, Unidade de Formação, Unidade de Sistemas de Gestão, Unidade de Administração; e, conta também com o Programa de Pós-Graduação Profissional em Gestão e Avaliação da Educação Pública (PPGP) oferecido pela Universidade Federal de Juiz de Fora (UFJF) por meio do Centro de Políticas Públicas e Avaliação da Educação (CAEd).

\section{ALGUMAS CONSIDERAÇÕES FINAIS}

O mapeamento realizado nesta pesquisa evidenciou um claro avanço na implantação de sistemas estaduais de avaliação da educação básica no Brasil. Tal processo tem gerado implicações significativas para a educação e a efetivação de seu direito.

Bertagna e Borghi (2011) apontam para uma relação entre a implantação de sistemas de avaliação da educação básica e a adoção de sistemas privados de ensino em redes públicas. Para as autoras, as redes e escolas acabam se lançando a diferentes e diversas estratégias para melhorar os resultados nas avaliações. Tal relação evidencia que os sistemas de avaliação, além de representarem um mecanismo de inserção da lógica de mercado na educação pública, ainda

\footnotetext{
${ }^{2}$ Consta ainda no sítio do CAED a assessoria de 11 sistemas de avaliação municipais; além do Jovem do Futuro, SESI/RS; SAEP/SENAI, Oratório São João Bosco. Mais informações em <http://www.portalavaliacao.caedufjf.net/>.
} 
induzem outras formas de privatização, dentre as quais, as autoras destacam a adoção de sistemas privados de ensino.

Também é preciso destacar a já mencionada reorganização do trabalho na escola e a restrição curricular resultante do foco nos resultados de desempenho denunciada por Freitas (2012). Para este autor, as escolas, aos poucos, naturalizam práticas de trabalho que acabam por concentrar e limitar o ensino ao treinamento dos alunos nas áreas/disciplinas avaliadas, por meio de testes quantitativos de proficiência, cerceando o conteúdo e a formação das crianças e dos adolescentes. Esta última questão é importante e ao mesmo tempo preocupante, principalmente, se considerarmos que a escola pública é um dos poucos espaços de acesso e produção do conhecimento por crianças e jovens das camadas populares, provocando, mais uma vez, restrições do direito à educação.

Outra implicação dos sistemas de avaliação para a efetivação do direito a educação é destacada por Borghi (2018). Para esta autora, a competitividade que embasa tais sistemas de avaliação naturaliza diferentes qualidades e compromete o ideal de qualidade para todos.

A 'educação-mercadoria' naturaliza a oferta diferenciada de educação e põe fỉm à perspectiva de uma educação de qualidade para todos. Nesse sentido, a educação mercadoria é um mal coletivo. No mercado, a qualidade se conforma a diferentes públicos e possibilidades de pagamento; enquanto bem público e direito de todos, numa perspectiva de universalidade, a educação não pode estar no âmbito privado de mercado. (BORGHI, 2018, p. 28).

Por fim, um último destaque, mas não menos importante refere-se aos custos da duplicação de sistemas de avaliação da educação para uma mesma rede de ensino. Há redes municipais que realizam avaliações do sistema nacional, do sistema estadual e do sistema federal, quase todos de maneira censitária, o que consequentemente impõe um custo financeiro alto para a sua realização e, em nossa compreensão, tais gastos poderiam estar sendo investidos na efetivação do direito a uma educação de qualidade para todos. 


\section{REFERÊNCIAS}

ADRIÃO, T. (Coord.) et al. Mapeamento das estratégias de privatização da redes estaduais de educação (20052015). 2018. Disponível em: <https://www.greppe.fe.unicamp.br/pt-br/mapeamento_da_insercao_do_setor_privado nas_redes_estaduais_de_educacao_2005_2015>. Acesso em: 10 de ago de 2018.

AFONSO, A. J. Para uma concetualização alternativa de accountability em educação. Educação \& Sociedade, Campinas, vol.33, n.119, p.471-484, jun. 2012.

BALL, S. J. Profissionalismo, gerencialismo e performatividade. Cadernos de Pesquisa, São Paulo, v 35, n. 126, dez. 2005. Disponível em: <http://www.scielo.br/pdf/cp/v35n126/a02n126.pdf>. Acesso em: 01 nov. 2013.

BALL, S.; YODELL, D. Privatización encubierta en la educación pública, Internacional de la Educación. Bruselas, 2008. 145 p. Disponível em: http://www.unionferroviaria.uy/wp-content/uploads/2017/04/Ball_S._y_Youdell_D. 2008_La_privatizaci\%C3\%B3n_encubierta_en_la_educaci\%C3\%B3n_p\%C3\%BAblica1.pdf. Acesso em: 9 de dez. de 2015.

BAUER A., TAVARES, T. Introdução. In: BAUER A., GATTI, B. A. e TAVARES, T. Vinte e cinco anos de avaliação de sistemas educacionais no Brasil: origem e pressupostos. Florianópolis: Insular Livros, v. 1, 2013, p. 1318.

BAUER, A.; PIMENTA, C.; HORTA NETO, J. L.; SOUZA, S. Z. Avaliação em larga escala em municípios brasileiros: o que dizem os números? Estudos em Avaliação Educacional, São Paulo, v. 26, n. 62, p. 326-352, maio/ago. 2015.

BERTAGNA, R.H.; Dimensões da formação humana e qualidade social: referência para os processos avaliativos participativos. In: DE SORDI, M.R.L.; VARANI, A.; MENDES, G.S.V. (Orgs.). Qualidade(s) da escola pública: reinventando a avaliação como resistência. Uberlândia/MG: Navegando Publicações, 2017, p. 31-46.

; BORGHI, R. F. Possíveis relações entre avaliação e sistemas apostilados privados em escolas públicas. Educação: Teoria e Prática, Rio Claro, v.21, n. 38, p. 132-146, 2011. Disponível em: <http://hdl.handle. net/11449/107430>. 2011. Acesso em: 01 nov. 2013.

BOGDAN, R., BIKLEN, S. Investigação qualitativa em educação: uma introdução à teoria e aos métodos. Porto: Porto Editora, 1994.

BONAMINO, A; SOUSA, S.Z. Três gerações de avaliação da educação básica no Brasil: interfaces com o currículo da/na escola. Educação e Pesquisa, São Paulo, v.38, n.2, p.373-388, abril-jun. 2012.

BORGHI, R. Que educação é pública? A privatização de um direito. Revista EccoS, n. 46, p. 19-32, mai.-jun. 2018.

BRASIL. Ministério da Administração e da Reforma do Estado. Plano Diretor da Reforma do Aparelho de Estado (PDRAE). Brasília: Câmara da Reforma do Estado, 1995.

Lei 13.005, de 25 de junho de 2014. Aprova o Plano Nacional de Educação - PNE. Diário Oficial da União, Brasília, DF, 26 jun. 2014, p. 1-7.

CARnEIRO, V.L. Política de avaliação e trabalho docente no ensino médio. 2013, 259f. Tese (Doutorado em educação). Instituto de Ciências da Educação, Universidade Federal do Pará, Belém, 2013.

CAEd. Centro de Políticas Públicas e Avaliação da Educação da Universidade Federal de Juiz de Fora - CAEd/UFJF. Disponível em: < http://institucional.caed.ufjf.br/>. Acesso em 03 de mar. de 2018

COSSO, D. A organização do trabalho pedagógico em uma escola de alto IDESP. 2013. 252 f. Dissertação (Mestrado em Educação) - Faculdade de Educação, Universidade Estadual Paulista, Campinas, 2013.

FILIPE, F.A.; BERTAGNA, R.H. Avaliação e qualidade no novo Plano Nacional de Educação: avanços e possíveis retrocessos? EccoS Revista Científica, Universidade Nove de Julho São Paulo, n. 36, jan.-abril, 2015 , p. 49-66. Disponível em: <http://www.redalyc.org/articulo.oa?id=715410610>. Acesso em: out. de 2015.

FREITAS, D. N. T. Avaliação educacional no Brasil, Campinas: Autores Associados, 2007.

FREITAS, L. C. de et al. Avaliação educacional: caminhando pela contramão. 3. ed. Petrópolis, RJ: Vozes, 2012.

Os reformadores empresariais da educação: da desmoralização do magistério à destruição do sistema público de educação. Educação \& Sociedade, Campinas, v. 33, n. 119, p. 379-404, abr.-jun. 2012. Disponível em: < http://www.cedes.unicamp.br > Acesso em: 27 dez. 2013. 
HORTA NETO, J. L.; JUNQUEIRA, R. D.; OLIVEIRA, A. S. Do SAEB ao SINAEB: prolongamentos críticos da avaliação da educação básica. In: HORTA NETO, J. L.; JUNQUEIRA, R. D.; OLIVEIRA, A. S. (Organizadores). Sistema de Avaliação da Educação Básica (Saeb): 25 anos. Em Aberto, Brasília, v. 29, n. 96, p. 9-11, maio/ago. 2016. Disponível em: 〈http://www.publicacoes.inep.gov.br/portal/download/2025> Acesso em: 15 de fevereiro de 2017.

HYPÓLITO, A. M. Políticas curriculares, Estado e Regulação. Educação \& Sociedade, Campinas, v. 31, n.113, p. 1337-1354, dez. 2010. Disponível em: <http://www.scielo.br/pdf/es/v31n113/15.pdf>. Acesso em: 01 nov. 2013.

out-dez. 2011.

Reorganização gerencialista da escola e trabalho docente. Educação: Teoria e Prática, v. 21, n.38, p. 59-78,

; GANDIN, L. A. Políticas de responsabilização, gerencialismo e currículo: uma breve apresentação. Revista eCurriculum, São Paulo, n.11, v.02, p. 335-341, ago., 2013.

INEP. Instituto Nacional de Estudos e Pesquisas Educacionais Anísio Teixeira. Índice De Desenvolvimento Da Educação Básica (IDEB). Nota técnica. 2012. Disponível em: <http://portal.inep.gov.br/web/saeb/as-avaliacoes-e-oideb>. Acesso em: 12 nov. 2013.

LIMA, L. C. Aprender para ganhar, conhecer para competir: sobre a subordinação da educação na "sociedade da aprendizagem”. São Paulo: Cortez, 2012. (Coleção Questões da nossa época; v. 41).

MAUÉS, O. C. As políticas educacionais e o sistema de avaliação. 2009. Disponível em: < http://www. anpae.org.br/ simposio2011/cdrom2011/PDFs/trabalhosCompletos/comunicacoesRelatos/0430.pdf >. Acesso em: 09 ago. 2013.

MELLO, L. R. de. A prática pedagógica avaliativa de uma escola do interior paulista. Dissertação (Mestrado em Educação) - Instituto de Biociências, Universidade Estadual Paulista Júlio de Mesquita Filho. Rio Claro, 2014.

MENEGÃO, R. de C. S. G. Os impactos da avaliação em larga escala nos currículos escolares. Práxis Educativa, Ponta Grossa, p. 641-656, v. 11, n. 3, set./dez. 2016. Disponível em: <http://www.revistas2.uepg.br/index.php/ praxiseducativa>. Acesso em: 31 jul. 2017.

NEWMAN, J; CLARK, J. Gerencialismo. Educação e Realidade, Porto Alegre, v. 37, n. 2, p. 353-381, maio/agosto 2012.

POLATO, A. A relação entre avaliações em larga escala e a organização do trabalho escolar em duas escolas públicas estaduais do interior de São Paulo. 198 p. 2014. Dissertação de Mestrado, Instituto de Biociências, Universidade Estadual Paulista, Rio Claro, 2014.

RAVITCH, D. Vida e morte do grande sistema escolar Americano: como os testes padronizados e o modelo de Mercado ameaçam a educação. Porto Alegre: Sulinas, 2011.

SADER, E. Público versus mercantil. Folha de S. Paulo, São Paulo, 19 jun. 2003. Disponível em: <https://www1.folha.uol.com.br/fsp/opiniao/fz1906200310.htm.> Acesso em: 20 de mar. de 2017.

SANTOS, A. Pedagogia do mercado: neoliberalismo, trabalho e educação no século XXI. Rio de Janeiro: Ibis Libris Ltda., 2012. v.1. 400 p.

SANTA CATARINA. Secretaria de Estado da Educação. Avaliação: As avaliações de larga escala e suas contribuições ao processo de ensino e aprendizagem. Florianópolis: SED, 2014.

SORDI, M. R. L. DE; VARANI, A.; MENDES, G. do S. C. V. (Orgs.). Qualidade(s) da escola pública: reinventando a avaliação como resistência. Uberlândia/MG: Navegando Publicações, 2017. 


\section{RESUMO}

O texto aborda o mapeamento de sistemas estaduais de avaliação brasileiros realizado no âmbito da pesquisa "Mapeamento das estratégias de privatização da educação básica no Brasil (2005-2015)" e tem por objetivo discutir os avanços do gerencialismo na educação básica. A metodologia de pesquisa de abordagem qualitativa se constituiu de levantamento nos sítios das secretarias estaduais de educação. No período de 2005-2015, os resultados evidenciaram 20 sistemas estaduais de avaliação, sendo que 14 deles foram implantados após o início do IDEB, em 2007. Tal processo de intensificação revela e tensiona a lógica de gestão gerencial no campo da educação pública. Destaca-se, também, que há uma duplicação de recursos destinados a avaliação da educação básica pelo governo federal e pelos governos estaduais, recursos estes que poderiam ser investidos na ampliação do direito a uma educação de qualidade para todos.

Palavras-chave: Sistemas de avaliação. Gerencialismo. Direito à educação.

\section{SYSTEMS OF EVALUATION OF STATES IN BRAZIL: ADVANCES OF MANAGERIAL ADMINISTRATION IN BASIC EDUCATION.}

\section{ABSTRACT}

This text approaches the mapping of the state evaluation system in Brazil developed in the scope of the research "Mapping the insertion of the private sector in the state education in Brazil (2005-2015)" and aims to the discussion of advances in managerialism for basic brazilian education. The methodology of research consists in qualitative approach made of survey of the sites of state education secretariats. In the period 2005-2015, the results shows 20 states evaluation systems, 14 of them was deployed after the beginning from IDEB, in 2007. This process of intensification reveals and stress the managerial administration logic in the field of public education. Stands out too the existence of the resources duplication that is destinated to basic education evaluation from de federal and state government that could be invested to amplify the education rights and quality to everybody.

Keywords: Evaluation systems, Managerialism, Education rights.

\section{SISTEMAS DE EVALUACIÓN DE LOS ESTADOS BRASILEÑOS: AVANCES DE EL GERENCIALISMO EN LA EDUCACIÓN BÁSICA.}

\section{RESUMEN}

El texto aborda el mapeo de sistemas de evaluación de los estados brasileños desarrollado en el ámbito de la investigación "Mapeo de las estrategias de privatización de la educación básica en Brasil (2005-2015)" y tiene por objetivo discutir los avances del gerencialismo en la educación básica brasileña. La metodologia de investigación con enfoque cualitativo se constituyó de recogida de datos en sitio web de las secretarías estatales de educación. En el período 2005-2015, los resultados pusieron en evidencia 20 sistemas estatales de evaluación, siendo que 14 de ellos fueron implantados después del inicio de IDEB, en año de 2007. Este proceso de intensificación manifiesta y tensiona la lógica de gestión gerencial en el campo de educación pública. Destaca, también, que hay una duplicación de recursos destinados a la evaluación de educación básica por el gobierno federal y por los gobiernos estatales, recursos estes que podrían ser invertidos en la ampliación de el derecho a una educación de calidad para todos.

Palabras-clave: Sistemas de evaluación. Gerencialismo. Derecho a educación. 